\title{
Müşteri Odaklı Sipariş Yanıtlama Sürecine İlişkin Bir Mobil Karar Destek Sistemi
}

\author{
Nilüfer YURTAY, Sakarya Üniversitesi Bilgisayar Mühendisliği Bölümü \\ Yüksel YURTAY, Sakarya Üniversitesi Bilgisayar Mühendisliği Bölümü \\ Emin GÜNDOĞAR, Sakarya Üniversitesi Endüstri Mühendisliği Bölümü \\ Hüseyin DEMİRCİ, Sakarya Üniversitesi Endüstri Mühendisliği Bölümü
}

Öz

\begin{abstract}
Üretici firmaların çoğu için, gelen siparişler doğrultusunda üretimin planlanması ve kontrolü oldukça zordur. Firmalar, bu planlama ve kontrolü yaparken, hammadde veya malzemenin girişinden, son ürünün dağıtımına kadar birçok süreci değerlendirmek durumundadırlar. Bu değerlendirme işlemleri, karar desteği sağlayan bilgisayar yazılımları ile daha hızlı ve doğru biçimde yapılabilmektedir. Teknolojinin yükselen trendi olan mobil destekli uygulamalar da, müşterilerin sipariş alışkanlıklarında değişikliklere yol açmıştır. Bu çalışmada, müşteriden mobil tabanl gelen siparişler doğrultusunda tasarım ve üretim yapan imalat firmalarn için hazırlanan ve siparişlerin zamanında karşılanabilmesini amaçlayan bir karar destek sistemi tanıtılmaktadir.
\end{abstract}

Anahtar Kelimeler: Kullanılabilirlik, Yapılabilirlik, Sipariş yanıtlama, Mobil Uygulama.

\begin{abstract}
For most manufacturing companies, planning and control of production is very difficult due to incoming orders. When planning and controlling, companies have to evaluate many processes from input of raw material or material to distribution of final product. These evaluation processes can be done faster and more accurately with computer software providing decision support. Mobile-based applications, which are the rising trend of technology, have also led to changes in customer ordering habits. In this study, a decision support system is prepared which is prepared for manufacturing companies who design and manufacture in accordance with the orders of customers from mobile based and aims to meet their orders on time.
\end{abstract}

Keywords: Available to Promise, Capable to Promise, Order Tracking, Mobile Application.

\section{Gíriş}

Küresel rekabete bağlı olarak üretici firmalar ayakta kalmak, pazar paylarını arttırmak ve müşteri memnuniyetini yüksek puanlara çıkarmak durumundadırlar. Pazar şartları üretim planlarında esnekliği zorunlu kılmaktadır. Günümüz müşterileri de daha hızlı geri dönüşler 
beklemekte, üretime ilişkin farklı taleplerde bulunabilmekte, talep ettikleri ürünün üretim süreçlerinde kendilerine özgü farklılıklar içermesini istemektedirler. Burada müşterilerin ilk beklentisi de "talep ettiğim ürün belirttiğim özelliklerde ve miktarda bana en kısa hangi sürede teslim edilebilir?" sorusunun cevabıdır.

Hızla yükselen teknolojik trend, üretici firmaları, bilgi sistemlerini tasarlarken, bilgisayar teknolojilerini maksimum düzeyde kullanmaya zorlamaktadır. Üretim firmalarının çok büyük bir kısmı, bilgisayar tabanlı üretim planlama ve kontrol yazılımları kullanmaktadır. $\mathrm{Bu}$ yazılımlar temel üretim planlama ve kontrol, üretim çizelgeleme, maliyet hesaplama, envanter kontrolü, malzeme ihtiyaç planlama, atölye kontrol, simülasyon vb. amaçlı olarak kullanmaktadırlar (Ovrin ve Diğerleri, 1990).

Bir işletmede müşteriden gelen teklif ya da siparişlerin karşılanması aşamasında ilk başvurulan sistem üretim planlanma sistemidir. Üretim planının amacı, teklif ya da sipariş edilen herhangi bir ürünün istenilen zamanda, istenilen miktarda ve nitelikte gerçekleştirilmesidir. Üretici firmalar, stoğa üretim yapabilecekleri gibi, siparişe göre montaj ya da siparişe göre üretim yapabilmektedirler. Stoğa üretim yapan ya da siparişe göre montaj yapan firmaların ürünlerinde esneklik yok denecek kadar azdır. Siparişe göre üretim yapan firmalarda ise, standart ürünlerin yanı sıra özel tasarım ürünler de önem arz etmektedir. Bu özel tasarımlar az ya da çok miktarda müşteriye seçenekler ve esneklik sunar. Mobilya üreten firmalar, bu tip çalışma sistemine iyi bir örnektir. Siparişe göre üretim yapan firmaların stok düzeyleri düşüktür ve genellikle yarı mamül stokları tercih edilir.

Literatürde Kullanılabilirlik/yapılabilirlik süreçleri ile ilgili pek çok çalışma mevcuttur. Xiong ve diğerleri(2003), imalat şirketlerindeki üretim planlamacılara karar desteği sağlamak üzere web tabanlı bir Kullanılabilirlik sistemi geliştirmişler ve dinamik ürün ağaç yapılarını önermişlerdir.

Pibernik (2005), ileri kullanılabilirlik süreçlerine ilişkin model ve algoritmalar hakkında teorik bir içerik sunmuştur. Cheng ve Cheng(2011), teslim tarihlerine ilişkin kara verme süreçlerinde Kullanılabilirlik hesaplamalarında bulanık mantık ve genetik algoritmaları kullanmışlardır. Alemany ve arkadaşları (2013), bir seramik karo üretim firması için matematiksel bir modele dayalı olarak kullanılabilirlik sistemi geliştirmiş, testler yapmış ve geliştirdikleri sistemin başarısını vurgulamışladır.

$\mathrm{Bu}$ çalışmada, stoğa göre üretim, siparişe göre montaj ve siparişe göre üretim yapan firmalara yönelik olarak geliştirilmiş olan, müşteri odaklı ve mobil destekli bir sipariş yanıtlama karar destek sistemi tanıtılmaktadır. Sistem kural tabanlı bir yaklaşımla geliştirilmiştir.

\section{Kullanılabilirlik/Yapılabilirlik Yaklaşımı}

Kullanılabilirlik (ATP-Available to Promise) hesaplamaları ile, müşteri siparişleri için, mevcut envanter miktarı üzerinde bir görüş niteliği sağlanır. Yapılabilirlik kontrolü (CTPCapable to Promise), alt montaj ya da üretimi yapılmış benzer ürünlerin, farklı ve opsiyonel müşteri siparişleri için kullanılabilmesine olanak tanır. Bu süreçte, üretim hatlarının mevcut durumu, envanter yeterliliği, işgücü kapasitesi büyük önem taşır. 
Şekil'1 de, bu çalışmada kullanılan, müşteri siparişi ile harekete geçen Kullanılabilirlik/Yapılabilirlik tabanlı mobil karar destek sisteminin şeması yer almaktadir(Yurtay,2004).

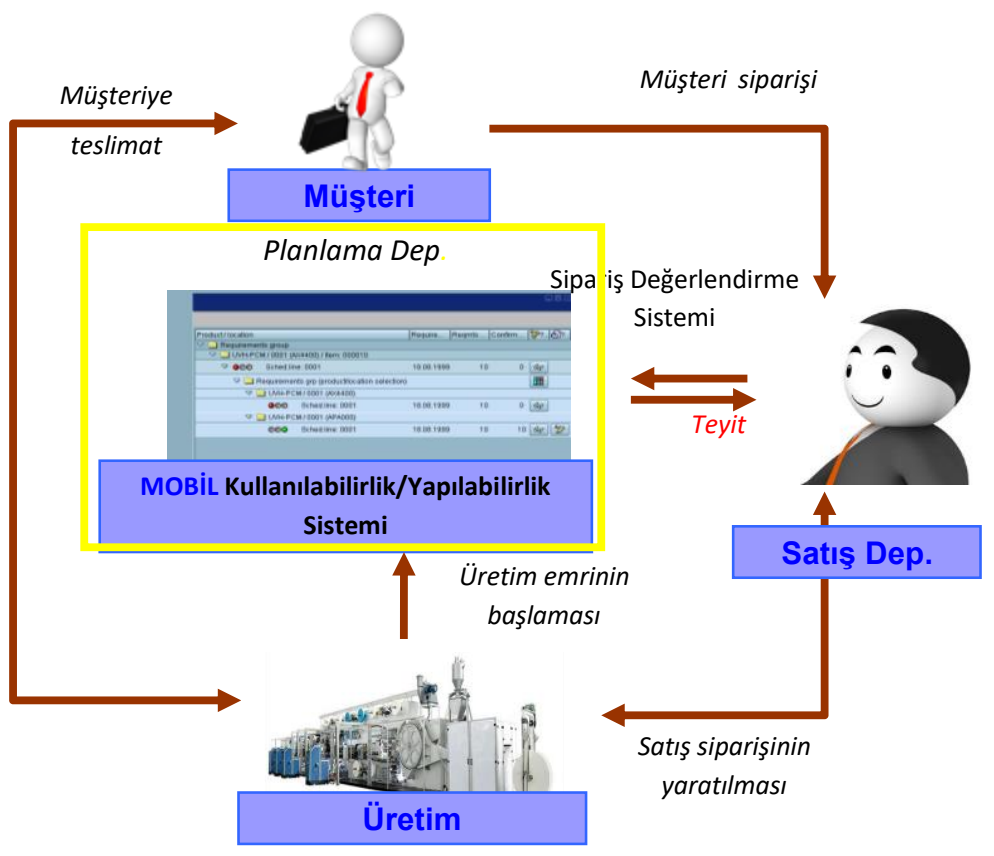

Şekil 1. Kullanılabilirlik/Yapılabilirlik Sistemi Genel Yapısı

\section{Sipariş Değerlendirme Sisteminin Yapısı}

Sistemin mobil arayüzü ile başlayan algoritmasında yer alan kurallar aşağıda çeşitli senaryolar aracılığı ile belirtilmiştir. Bu kurallar üretim programcisı ile zaman zaman etkileşimli olarak işlemektedir. Şekil 2'de müşteri siparişlerinin tiplerine göre değerlendirilme şemasında belirtildiği üzere, müşterilerin teslim tarihini kendilerinin belirlemesi ya da belirlememesi durumlarına göre sipariş yanıtlama gerçekleşmektedir. $\mathrm{Bu}$ süreçde ürünler, standart ya da opsiyonel olmaları durumuna göre ayrı ayrı ele alınmaktadır.

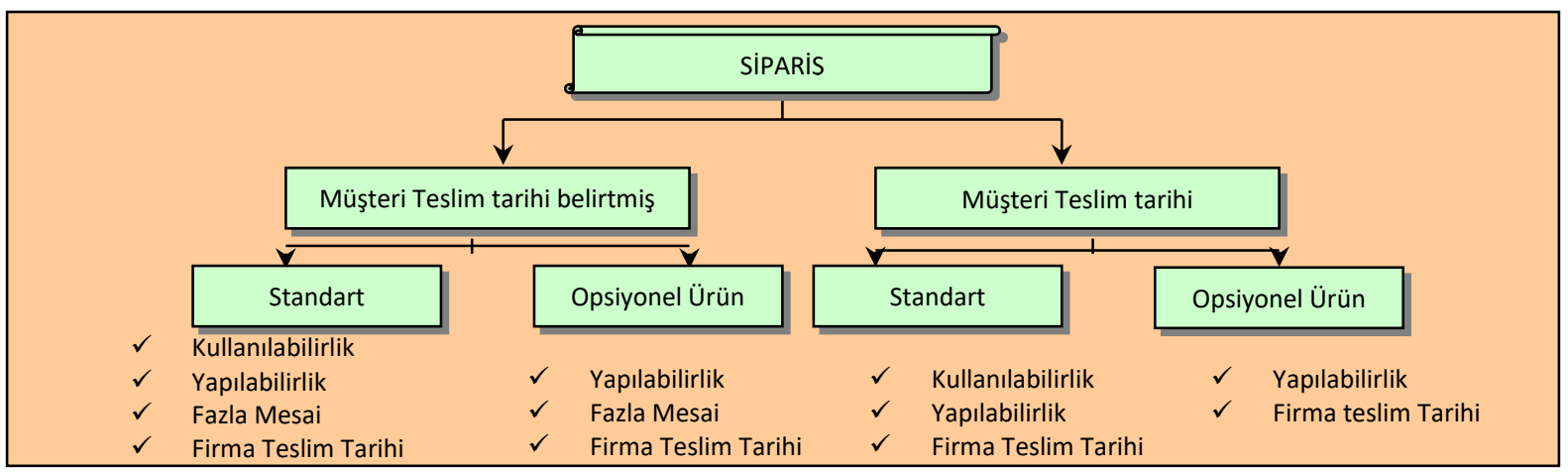

Şekil 2. Mobil Kullanılabilirlik/Yapılabilirlik Sisteminde Müşteri siparişlerinin değerlendirmesi 


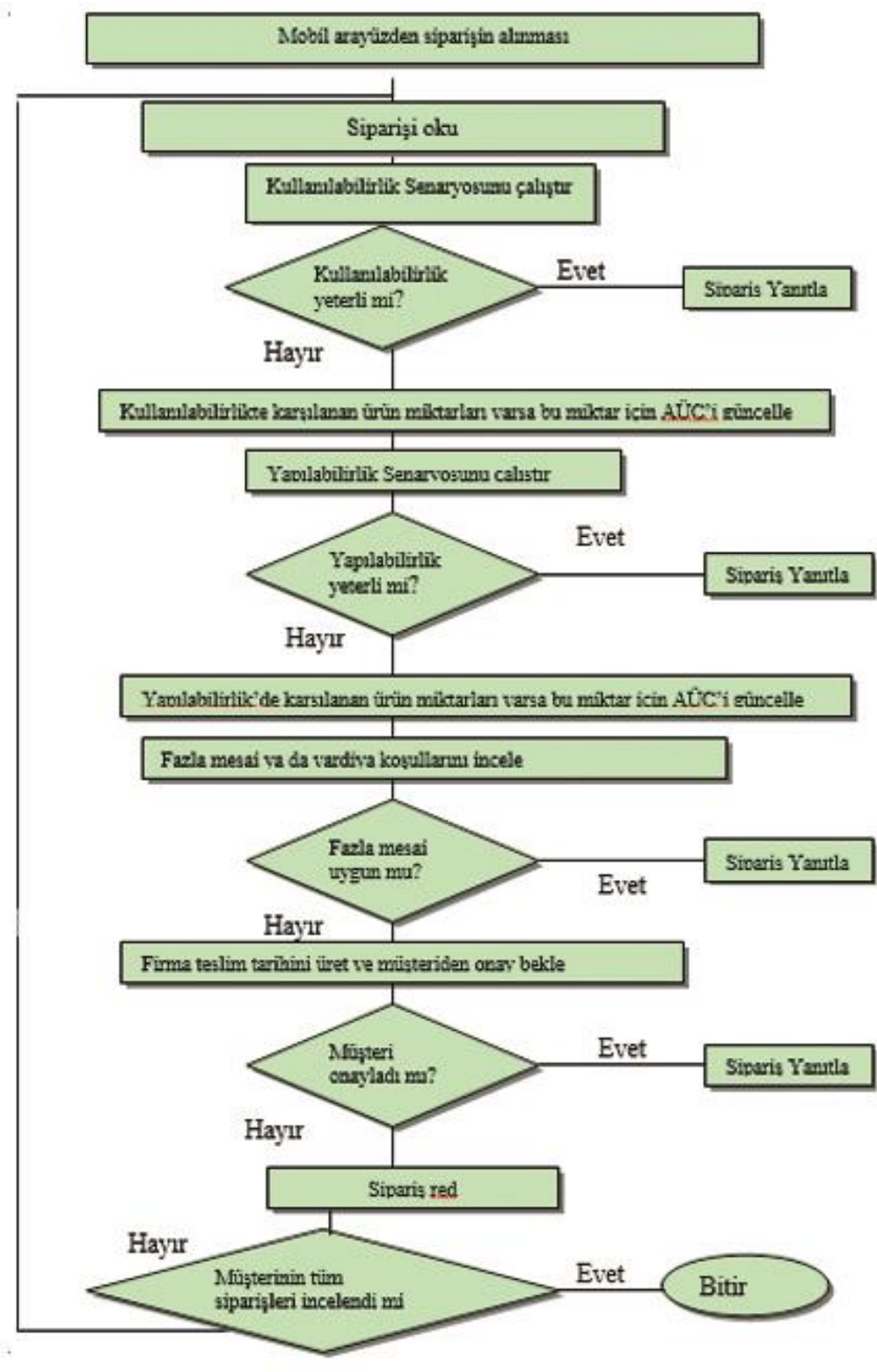

Şekil 3. Mobil Kullanılabilirlik/Yapılabilirlik Sistemindeki ana prosesler

Şekil 3'de ise mobil kullanılabilirlik/Yapılabilirlik sisteminin ayrıntılı akış şeması gösterilmektedir. Sistemde kullanılabilirik, yapılabilirlik, fazla mesai ve vardiyalı sistem alternatifleri için ayrı ayrı senaryolar oluşturulmuştur. Kullanılabilirlik senaryosunda, müşterinin sipariş ettiği miktardaki ürünün müşterinin talep ettiği tarihte stoklardan ya da ana üretim çizelgesinden(AÜÇ) faydalanarak herhangi bir üretime gitmeksizin karşılanıp karşılanamayacağı incelenmektedir. Müşterinin belirlediği teslim tarihine karşılık gelen üretim haftası için ana üretim çizelgesinde kullanılabilirlik hesabı yapılmakta ve buradaki değerler doğrultusunda ürün talebinin tamamının ya da bir kısmının karşılanıp karşılanamayacağı belirlenmektedir. Talebin bir kısmının kullanılabilirlik'den karşılanamaması durumunda CTP ve gerekirse Fazla Mesai senaryoları devreye girmektedir. 
Mobil Kullanılabilirlik/Yapılabilirlik Sistemi çalıştırıldığında müşteriden gelen siparişler doğrultusunda, firmanın stratejik amaçlarına uygun olarak belirlenen kurallar tabanını çalışmakta ve üretim planlayıcıya karar desteği sağlayacak olan bir rapor hazırlamaktadır. Şekil 4'de bir müşteri sipariş ana ekranı yer almaktadır. Şekil 5'da sipariş yanıtlama ekranı gösterilmektedir. Yanıtlama ekranında, sistemin cevabının ilgili müşterinin talep ettiği tarihte ürün ile ilgili yanıtlamanın olumlu olmadığı ve alternatif yeni bir teslim tarihinin önerildiği görülmektedir. Müşteri onayı durumuna göre sipariş kesinleşecektir.

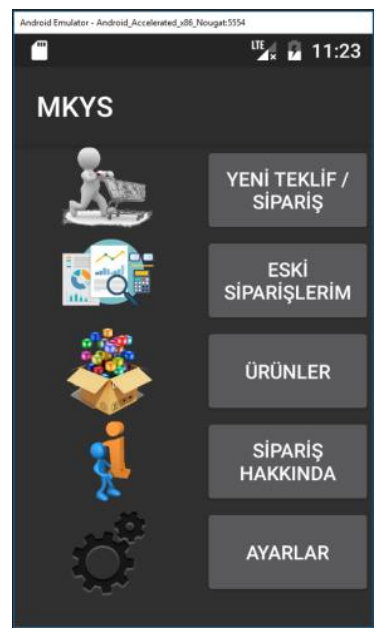

Şekil 4. Mobil Kullanılabilirlik/Yapılabilirlik Sistemindeki Müşteri Sipariş Ekranı

Sistem, müşterinin istediği tarihte, müşterinin istediği üründen, müşterinin istediği miktarda teslim edebilmenin yollarını aramaktır. Kullanılabililik ya da yapılabilirlik bilgilerini maksimum kapasitede kullanır. Eğer bu amaca ulaşamamış ise, müşteri kaybını engellemek amacıyla, mümkün olan en kısa teslim tarihini belirleyerek müşteriyi ikna etmeye yönelik bir senaryo üretir. Sistemin bir diğer kazanımı ise, bilgi yetersizliği, tecrübesizlik, dikkatsizlik vb. türden kişisel hatalara bağlı olarak oluşabilecek yanlış hesaplamaların miktarlarında önemli azalmalar sağlamaktır.

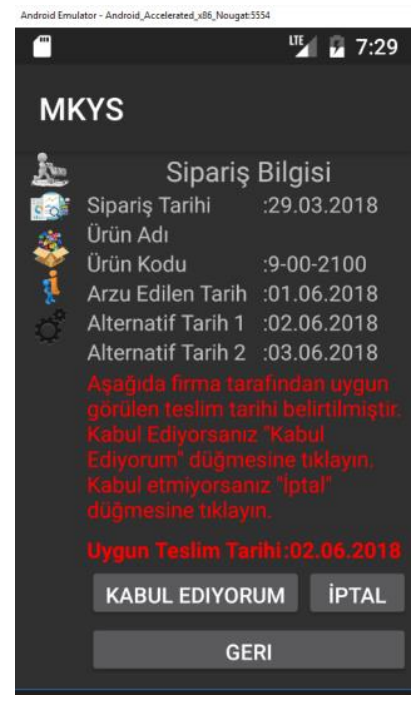

Şekil 5. Mobil Kullanılabilirlik/Yapılabilirlik Sistemindeki Müşteri Sipariş Yanıtlama Ekranı 
Geliştirilen mobil Kullanılabilirlik/Yapılabilirlik Sistemi, orta ölçekli firmalar için pek çok avantaj sağlamaktadır. Bunlar arasında, sipariş süreçlerinde hızlı yanıtlamanın gerçekleşmesi, buna bağlı olarak global pazarda müşteri kayıplarını önlenmesi ilk sırada yer almaktadır. Bir diğer avantaj, müşteri beklentilerine göre, arge faaliyetleri daha gerçekçi olarak planlanabilmesidir. Ayrıca, sistemin çalışması esnasında çalışan senaryolar arşivlenmekte, bu arşivler ve gerçekleşen siparişler birlikte ele alınarak, veri madenciliği yöntemleri ile, ileriye dönük olarak daha başarılı sipariş öngörülerinde bulunulabilmektedir.

\section{Sonuç}

Üretim işletmeleri, beklenmedik bir talep geldiğinde bunları karşılayabilmek ve müşterisini kaybetmemek için stok seviyelerini ideal tutmak aynı zamanda da müşteri siparişlerini zamanında karşılamak niyetindedir. Durum böyle olunca en ideal çözüm; stok maliyetlerini ve kaybedilecek müşteri maliyetlerini en aza indirmektir. Bu da uygun şekilde hazırlanmış ana üretim çizelgesi ile beraber stratejik planlamaya da bağlıdır. Mobil destekli Kullanılabilirlik/Yapılabilirlik Sistemi, sanal bir üretim programcısı gibi çalışarak, içerisindeki kurallar doğrultusunda aldığı hızlı ve doğru kararlar ile bu yönde önemli bir karar desteği sağlamaktadır. Müşteriler mobil telefonundan sipariş teklifinde bulunabilmekte ve online yanıt alabilmektedir. Tanımlanan ürün opsiyonları sayesinde, müşteri memnuniyeti arttırılmaktadır. Müşteri memnuniyeti satışların artmasında da önemli bir etken olmaktadır.

\section{KAYNAKÇA}

ALEMANY, M.,M.,E.,LARIO, F.,C.,ORTIZ, A.,GOMEZ, F.," Available-To-Promise modeling for multi-plant manufacturing characterized by lack of homogeneity in the product: An illustration of a ceramic case", Applied Mathematical Modelling, Volume 37, Issue 5, 1 March 2013, Pages 3380-3398.

CHENG, C.,B., CHENG, C.,J.," Available-to-promise based bidding decision by fuzzy mathematical programming and genetic algorithm", Computers \& Industrial Engineering, Volume 61, Issue 4, November 2011, Pages 993-1002.

OVRIN, P., J. OLHAGER, B. RAPP, “Computer-based manufacturing planninng and control systems in small companies", Peter European Journal of Research, 45, 106-112, 1990.

PIBERNIK,R., "Advanced available-to-promise: Classification, selected methods and requirements for operations and inventory management", International Journal of Production Economics", Volumes 93-94, 8 January 2005, Pages 239-252

XIONG, M., TOR, S.B., KHOO,L.P., CHEN, C.H," A web-enhanced dynamic BOM-based available-to-promise system", International Journal of Production Economics, Volume 84, Issue 2, 11 May 2003, Pages 133-147.

YURTAY, N., "Siparişe Montaj ve Stoğa Üretim İçin İnternet Destekli Kural Tabanlı Bir ATP/CTP sistemi", Doktora Tezi, 2004. 